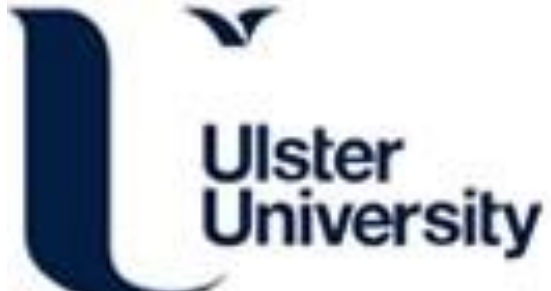

\section{Processes and patterns of flow, erosion, and deposition at shipwreck sites: a computational fluid dynamic simulation}

Quinn, R., \& Smyth, TAG. (2018). Processes and patterns of flow, erosion, and deposition at shipwreck sites: a computational fluid dynamic simulation. Archaeological and Anthropological Sciences, 10(6), 1429-1442. https://doi.org/10.1007/s12520-017-0468-7

Link to publication record in Ulster University Research Portal

\section{Published in:}

Archaeological and Anthropological Sciences

Publication Status:

Published (in print/issue): 30/09/2018

DOI:

10.1007/s12520-017-0468-7

\section{Document Version}

Author Accepted version

\section{General rights}

Copyright for the publications made accessible via Ulster University's Research Portal is retained by the author(s) and / or other copyright owners and it is a condition of accessing these publications that users recognise and abide by the legal requirements associated with these rights.

\section{Take down policy}

The Research Portal is Ulster University's institutional repository that provides access to Ulster's research outputs. Every effort has been made to ensure that content in the Research Portal does not infringe any person's rights, or applicable UK laws. If you discover content in the Research Portal that you believe breaches copyright or violates any law, please contact pure-support@ulster.ac.uk. 


\section{Processes and patterns of flow, erosion, and deposition at shipwreck sites: a computational fluid dynamic simulation}

\section{R. Quinn' and T.A.G. Smyth2}

I School of Geography and Environmental Sciences, Ulster University, Coleraine BT52 ISA, Northern Ireland, RJ.Quinn@ulster.ac.uk (author for correspondence) Australia

\section{Keywords}

13 Computational fluid dynamics; shipwreck; fluid flow; site formation processes;

14 hydrodynamics; scour; deposition

\section{Abstract}

Shipwreck sites are open systems, allowing the exchange of material and energy across system boundaries. Physical processes dominate site formation at fully submerged wreck sites, and in turn influence chemical and biological processes at many stages of site formation. Scouring presents a fundamental yet poorly understood threat to wreck sites, and the processes and patterns of erosion and deposition of sediments and artefacts at wreck sites are poorly understood. Laboratory and field based experiments to study these phenomena are time-consuming and expensive. In this study open-source computational fluid dynamic (CFD) simulations are used to model the processes and patterns of flow, erosion, and deposition at fully submerged wreck sites. Simulations successfully capture changes in the flow regime in the environment of the wreck as a function of incidence angle, including flow contraction, the generation of horseshoe vortices in front of the wreck, the formation of lee-wake vortices behind the structure, and increased turbulence and shear stress in the lee of the wreck site. CFD simulations demonstrate that horseshoe vortices control scour on the upstream face of structure, but play a minimal role in scouring on the lee side. Lee-wake vortices dominate behind the structure, with low pressure zones in the lee of the wreck capturing flow. The amplification and reduction of wall shear stress and turbulent kinetic energy in the lee of the vessel form distinctive patterns in relation to flow direction, with areas of amplified and reduced wall shear stress and turbulent kinetic energy demonstrating excellent spatial correlation with erosional and depositional patterns developed at real-world wreck sites. 


\section{Introduction}

41 Erosional and depositional features form in the lee of obstacles on the seafloor and are

42 widely reported from all offshore environments (Whitehouse, 1998). Natural features such

43 as rock outcrops and anthropogenic obstacles including breakwaters, pilings, foundations,

44 and shipwrecks give rise to sediment deposits and scour features in their wake (Astley et al.,

45 2014; Whitehouse et al., 2010). An understanding of the processes that form and maintain

46 these erosional and depositional features is critical as they can control the stability and long-

47 term integrity of submerged anthropogenic structures.

In archaeological investigations, scouring is reported widely, from nearshore submerged wreck sites in shallow water (Arnold et al. 1999; Baeye et al., 2016; Caston 1979; McNinch et al. 200I; Quinn et al. 1997; Wheeler 2002) to deep-water sites on the continental shelf and beyond (Ballard et al. 2000, 2002; McCann and Oleson 2004; Uchupi et al. 1988). Scour is reported from intact and scattered wreck sites (Arnold et al. 1999; Caston 1979; McNinch et al. 2001; Quinn 2006; Wheeler 2002) and from individual artifacts and artifact scatters (Ballard et al. 2000, 2002; McCann and Oleson 2004). In maritime archaeology the focus on site formation theory (Muckelroy 1978; O'Shea 2002; Quinn 2006; Stewart 1999; Ward et al. 1999) and a general acceptance that physical processes dominate site formation in the early stages (Ward et al. 1999) suggest that a greater understanding of scouring and associated depositional and erosional processes and patterns at wreck sites is important.

The aim of this study is to investigate the mechanisms responsible for the formation and evolution of scour and depositional features under secondary flows using computational fluid dynamic (CFD) simulations (Smyth and Quinn, 2014). Until now, we have only been able to investigate patterns of erosion and deposition through field-based investigations (Caston, 1979; Astley et al., 2014) or laboratory based physical models (Saunders, 2005; Testik et al., 2005), while the complex processes giving rise to the patterns have been difficult, timeconsuming and expensive to investigate. CFD allows us to examine these processes in detail. The results represent a significant breakthrough in understanding fluid flow and erosional and depositional processes and patterns at submerged wreck sites.

2. Theory: patterns of erosion and deposition at wreck sites

Scouring is associated with areas of elevated shear stress, where shear stress exerted by moving water is proportional to the square of the flow velocity. In the ocean, the majority of erosion, deposition, and transport of sediment takes place in the boundary layer adjacent to 
the seafloor. The extent to which sediment movement takes place depends on the amount of turbulence (turbulent kinetic energy, TKE) and shear stress (wall shear stress, WSS) exerted on the bed. Sediment moves on the seafloor when the shear stress at the bed exceeds the frictional and gravitational forces holding the grains to the bed (i.e. when critical shear stress is reached). Marine scour occurs when sediment is eroded by oscillatory flows such as waves, by directional flows (tidal, river, or density induced), or a combination of both (Whitehouse 1998). The introduction of an object (shipwreck or engineering structure) to the seafloor may initiate scour (Soulsby 1997; Whitehouse 1998; Quinn 2006), and scour processes can ultimately lead to complete failure and collapse of the structure (Soulsby 1997; Whitehouse 1998). Scour signatures are widely reported from the marine environment, and their development and importance in short- and long- term site evolution are noted in shipwreck archaeology (Arnold et al. 1999; Baeye et al., 2016; Caston 1979; McNinch et al. 200I; Quinn 2006; Trembanis and McNinch 2003; Uchupi et al. 1988; Ward et al. 1999).

In summary, the introduction of an object to the seafloor leads to an increase in flow velocity (due to continuity) and turbulence (due to the generation of vortices; Whitehouse 1998). Scouring subsequently results in the lowering of the seabed due to flow velocity increase near the object, a resulting increase in the local Shields parameter (a nondimensional number used to calculate the initiation of motion of sediment in a fluid flow), and subsequent divergences in the sediment transport regime (Voropayev et al. 2003). Therefore the introduction of an object to the seafloor causes changes in the flow regime in its immediate environs, resulting in one, or a combination of, the following: flow contraction; the formation of a horseshoe vortex in front of the structure; the formation of lee-wake vortices behind the structure (sometimes accompanied by vortex shedding); turbulence; the occurrence of reflection and diffraction waves; wave breaking; and sediment liquefaction promoting material loss from the site (Sumer et al. 200I). These processes increase local sediment transport and subsequently lead to scour (Sumer et al. 200I).

The flow around a shipwreck is three-dimensional and consists of two basic structures (Testik et al. 2005; Quinn, 2006): the horseshoe vortex formed at the front of the structure and the lee-wake vortex formed behind. The horseshoe vortex is created by the rotation of the incoming flow, and under the influence of the adverse pressure gradient produced by the structure, rolls up to form a swirling vortex around the structure, and trails off down-flow

110 (Sumer et al. 1997). Vortex shedding sometimes occurs, where self-propelling, closed ring 111 structures are formed and transported by the flow (Testik et al. 2005). Lee wake vortices 112 are formed by the rotation in the boundary layer over the surface of the object. End effects 
113 from the bow and stern of the vessel play a dominant role in the flow pattern and strongly

114 modify the structure of vortices (Testik et al. 2005; Quinn, 2006). Lee wake vortices

115 emanating from the surface of the object are brought together in the vicinity of the

116 structure due to flow convergence (Hatton et al. 2004; Smith et al. 2004; Testik et al. 2005).

117 Additionally, two counter-rotating vortices form a vortical region in the near wake on the

118 lee side of the object (Testik et al. 2005).

120 When scour occurs on fine-grained (silt or clay) seabeds, the eroded material is carried 121 away from the wreck site in suspension (Baeye et al., 2016), leaving a seafloor depression 122 that may not readily be in-filled by natural processes (Whitehouse et al. 20II). When scour

123 occurs in coarse-grained deposits (sand or gravel), it usually results in local deposition of the

124 eroded material. As the majority of wrecks of archaeological interest are located in shelf

125 seas dominated by sand- and/or gravel-substrates, this study focuses on sites located in

126 coarse-grained deposits only.

128 Caston (1979), Saunders (2005), Quinn (2006), and Quinn et al. (2016) previously illustrated

129 complex patterns in the formation of scour and depositional features at wrecks sites, and

130 noted the size and morphology of scour features are sensitive to the orientation of the

131 obstacle relative to flow. Knowledge of these patterns and inferred processes have been

132 largely derived from field observation through remote sensing (Caston, 1979; Quinn, 2006)

133 and laboratory-based physical models (Saunders, 2005; Testik et al., 2005). However, the

134 characteristics of the flows that develop behind shipwrecks, the stresses and turbulences

135 that are induced by the obstacle, and their relationship with the angle of incidence of the

136 flow remain poorly understood.

138 In engineering, scour is broadly classified as local scour (e.g. steep-sided scour pits at

139 individual obstructions), global or dishpan scour (shallow broad depressions developed

140 around installations), or general seabed movement, resulting in erosion, deposition or

141 bedform development (Whitehouse 1998). In this study, the terms local scour (steep-sided

142 scour pits formed in the immediate area of the wreck) and wake scour (shallower elongate

143 extended linear depressions formed parallel to peak flow) are adopted following Saunders

144 (2005).

\section{3. Material and methods}

$148 \quad 3.1$ Experimental setup 
150 CFD simulations were conducted using a 'generic' hull shape (Figure I) to represent the 151 shipwreck. The hull of Jylland (launched 1860), one of the world's largest wooden warships

152 (designed as both a screw-propelled steam frigate and a sail ship), was modelled in SketchUp

153 and converted to a stereolithography (STL) file. SnappyHexMesh, the native mesh generator

154 of the CFD software package OpenFOAM®, was used to produce the final three-

155 dimensional computational domain. The hull was positioned in the centre of a $500 \times 500 \times$

$15640 \mathrm{~m}$ domain which increased in resolution from $25 \mathrm{~m}$ at the boundaries to $0.125 \mathrm{~m}$ at the

157 wreck site, finer than the resolution used by Smyth and Quinn (2014) at which mesh

158 independence was achieved. The bottom $2 \mathrm{~m}$ of the hull was placed beneath the seabed,

159 leaving $5 \mathrm{~m}$ of the structure exposed. The seabed was prescribed a roughness length $\left(\mathrm{z}_{0}\right)$ of

$1600.06 \mathrm{~m}$, the equivalent of rippled sand (Johns, 1983), while the water surface was defined to

161 produce zero gradient with the flow. This model was designed to mimic a typical fully

162 submerged wreck site in a shelf sea environment, and the domain size and resolution was

163 designed to optimize model run times while capturing near-field and far-field erosional and

164 depositional signatures.

\subsection{Approaching flow}

The secondary flows that develop in the presence of a shipwreck are formed by modification of the approaching flow. Flow can be described using the Navier-Stokes equations; however, calculation of the complete equations in fully turbulent flow is computationally prohibitive.

171 In these simulations flow was modelled using the Reynolds-averaged Navier-Stokes (RANS)

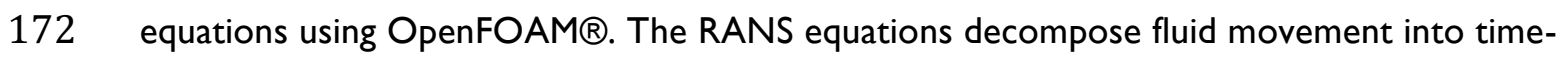

173 averaged and fluctuating quantities, providing an approximate solution of the Navier-Stokes 174 equations.

176 TKE and turbulence dissipation rate $(\varepsilon)$ was calculated using renormalization group theory

177 (RNG). This method was employed due to the excellent comparison between measured and 178 modelled data in a wind tunnel over a backward facing step (Yakhot et al., 1992) and in field 179 experiments over three-dimensional natural complex landforms (Smyth et al., 2013; Hesp et 180 al., 2015).

As flow in the lee of a shipwreck is intrinsically unsteady, the large time-step transient solver 183 for incompressible flow (PIMPLE) was used. Simulations were considered complete once the 184 initial solver residuals representing the absolute error of a variable were 5 orders of 185 magnitude smaller than the maximum calculated. To represent determinative flow 186 conditions, 100 time steps of each simulation were averaged from which flowlines (the path 
traced by a massless particle), velocity, turbulent kinetic energy, wall shear stress and

188 pressure were visualized.

190 Fluid flow at the inlet of the computational domain was defined as a steady logarithmic

191 boundary layer equal to $1.30 \mathrm{~m} \mathrm{~s}^{-1} 2 \mathrm{~m}$ above the seabed. Simulations were conducted at $15^{\circ}$

192 increments, from perpendicular $\left(90^{\circ}\right)$ to parallel to flow $\left(0^{\circ}\right)$; a total of 7 simulations. To

193 represent water at $10^{\circ} \mathrm{C}$, the fluid was prescribed a kinematic viscosity of $1.307 \mathrm{~m}^{2} \mathrm{~s}^{-1}$.

\section{Results}

\section{I General hydrodynamic environment in the lee of the hull}

The general hydrodynamic environment in the lee of the submerged hull structure is illustrated in a series of 3-dimensional CFD visualizations (Figure 2). Horizontal flow separation occurs in the formation of two opposing vortices in the lee of the wreck (Figure $2 a)$, with low-velocity zones developing on the upstream and downstream side of the hull structure, and high velocity zones developing in the water column above the wreck and on the seabed at the bow and stern of the vessel (Figure 2a). A high-pressure zone is induced on the upstream side of the hull and a low pressure zone formed on the downstream side (Figure 2b). Patterns of turbulence in the water column and on the seafloor (Figure 2c) largely mirror the patterns in velocity, with a zone of high turbulence developed in the water column on the downstream side of the hull and zones of elevated turbulence developed on the seafloor on the upstream side of the wreck and at the bow and stern (Figure 2c).

The flow velocity and patterns of pressure $(P)$, WSS, and TKE are now discussed as a function of incidence at increments of $15^{\circ}$; from the hull orientated perpendicular to flow (at $90^{\circ}$ ) to parallel to flow (at $0^{\circ}$ ) (Figures 3-9; Table I).

\subsection{Hull at $90^{\circ}$ to flow}

217 Figure 3 shows typical CFD simulations for the submerged hull at an incident angle of $90^{\circ}$

218 under a uni-directional flow of velocity $1.3 \mathrm{~m} \mathrm{~s}^{-1}$. At this angle of incidence, flow and stress

219 patterns are almost symmetrical around a flow-parallel plane of symmetry through the

220 centre of the hull. On encountering the hull, an adverse pressure gradient induces small

221 clockwise horseshoe vortices at the near-vertical wall, and the approaching flow is diverted

222 over and around the structure, increasing in velocity (Figures $3 \mathrm{~b}$ and $3 \mathrm{c}$ ). Flow contraction

223 occurs at the bow and stern. Horizontal flow separation takes place, with a counter rotating 
224 low-velocity vortex pair developing in the low-pressure zone downstream of the hull

225 (Figures 3a to 3c). Overall, the flow velocity structure is complex (Figure 3c), but virtually

226 symmetrical around the plane. Low velocity zones form immediately upstream and

227 downstream of the hull. Two crescentic regions of increased velocity originate from the bow

228 and stern, converging downstream. A central high-velocity, flow-parallel zone is located

229 between the two counter-rotating vortices (Figure 3c). A high-pressure zone develops

230 upstream, probably by pressure-induced down-flow on the seafloor (Figure 3d). Immediately

231 in the lee of the hull, a low pressure zone develops and extends downstream for

232 approximately one full length. This is in turn replaced by a zone of intermediate pressure

233 (Figure 3d). Two crescentic regions of amplified wall shear stress (WSS, Figure 3e) and

234 turbulent kinetic energy (TKE, Figure $3 f$ ) originate at the bow and stern, coincident with the

235 zones of elevated flow velocity modelled in the CFD simulations (Figure 3c). Furthermore, in

236 the TKE simulation, two symmetrical turbulent zones form parallel to dominant flow,

237 emanating approximately one ship-length from the hull. Zones of low WSS and low TKE

238 form immediately in the lee of the hull and on the upstream side of the structure.

4.3 Hull at $75^{\circ}$ to flow

242 As the approaching flow becomes more acute, the patterns developed in the CFD simulation

243 become increasingly asymmetrical. Figure 4 shows typical CFD simulations for the

244 submerged hull at an incident angle of $75^{\circ}$ under a uni-directional flow of velocity $1.3 \mathrm{~m} \mathrm{~s}^{-1}$.

245 At this angle, flow contraction, flow separation and the development of the horseshoe

246 vortex on the upstream side of the hull structure are observed (Figures $4 \mathrm{a}$ and $4 \mathrm{~b}$ ).

247 Counter-rotating low-velocity vortices are again developed in the lee of the hull, with the in-

248 flow vortex dominant. The low-velocity (Figure 4c) and low-pressure (Figure 4d) zones

249 developed downstream are skewed along a line parallel to the flow, with greater flow-

250 contraction and higher velocities recorded at the bow than the stern (Figures 4b and 4c).

251 WSS and TKE patterns broadly correlate (Figures $4 \mathrm{e}$ and $4 \mathrm{f}$ ) with zones of high shear stress

252 and turbulence extending from the bow and stern, with higher values recorded at and in the

253 lee of the bow section. Additionally, two asymmetric turbulent zones form downstream of

254 the hull, separated and surrounded by zones of low turbulence, elongated parallel to the

255 flow direction (Figure 4f).

4.4 Hull at $60^{\circ}$ to flow

259 Figure 5 shows typical CFD simulations for the submerged hull at an incident angle of $60^{\circ}$

260 under a uni-directional flow of velocity $1.3 \mathrm{~m} \mathrm{~s}^{-1}$. At $60^{\circ}$, the upstream vortex developed at 
261 the bow almost completely dominates vortex development in the lee of the structure. A

262 small downstream vortex is developed in the lee of the stern, but it is much smaller in terms

263 of magnitude and space (Figures $5 \mathrm{a}$ and $5 \mathrm{~b}$ ). Flow contraction and downward pressure is

264 greater at the bow (Figures $5 \mathrm{a}$ to $5 \mathrm{~d}$ ), with the low pressure zone developed in the lee of

265 the vessel skewed in direction of flow. Again, the WSS and TKE plots correlate (Figures $5 \mathrm{e}$

266 and 5f) with high shear stress and turbulent areas developed at the bow and two zones of

267 high WSS/TKE converging downstream of the hull, roughly parallel to flow.

4.5 Hull at $45^{\circ}$ to flow

271 Figure 6 shows typical CFD simulations for the submerged hull at an incident angle of $45^{\circ}$

272 under a uni-directional flow of velocity $1.3 \mathrm{~m} \mathrm{~s}^{-1}$. At $45^{\circ}$, the rotating vortex originating at

273 the bow of the vessel dominates the 2D and 3D flow line simulations (Figures 6a and 6b).

274 The vortex originating at the stern is negligible (Figure 6b), although still present. High

275 velocity (Figure 6c) and high pressure (Figure 6d) zones develop in the lee of the hull, with

276 low velocity and low pressure zones at their edges. Strong correlation between the WSS

277 (Figure 6e) and TKE (Figure 6f) plots are evident, with amplification of both in flow-parallel

278 zones in the lee of the hull. Both zones are bordered by narrow bands of low WSS and low

279 TKE.

Figure 7 shows typical CFD simulations for the submerged hull at an incident angle of $30^{\circ}$ under a uni-directional flow of velocity $1.3 \mathrm{~m} \mathrm{~s}^{-1}$. At $30^{\circ}$, the rotating vortex originating at the bow of the vessel again dominates (Figures $7 \mathrm{a}$ and $7 \mathrm{~b}$ ), with the ensuing more open vortex aligned at $30^{\circ}$, parallel to the approaching flow. High velocity (Figure 7c) and high pressure (Figure 7d) zones develop in the lee of the hull, again with low velocity and low pressure zones at their edges. Strong correlation between the WSS (Figure 7e) and TKE

289 (Figure 7f) plots are once more evident, with amplification of both in flow-parallel zones in 290 the lee of the hull. Both zones are bordered by narrow bands of low WSS and low TKE, 291 almost symmetrical in nature about a flow-parallel plane. Zones of high WSS and TKE are also evident at the front and originating from the bow of the hull. under a uni-directional flow of velocity $1.3 \mathrm{~m} \mathrm{~s}^{-1}$. At $15^{\circ}$, with the elongate hull structure 
aligned almost parallel to approaching flow, a single tight rotating vortex originates from the vessel (Figures $8 \mathrm{a}$ and $8 \mathrm{~b}$ ), parallel to flow. A high velocity (Figure 8c) zone extends downstream from the structure, accompanied by a low velocity zone below it. High and low pressure zones are developed at the front and back of the bow section respectively (Figure 8d). Strong correlation between the WSS (Figure 8e) and TKE (Figure 8f) plots are again evident, with amplification of both in flow-parallel zones in the lee of the hull. Both zones are bordered at the bottom by narrow bands of low WSS and low TKE. Zones of high WSS and TKE are also evident at below the hull.

Figure 9 shows typical CFD simulations for the submerged hull at an incident angle of $0^{\circ}$ under a uni-directional flow of velocity $1.3 \mathrm{~m} \mathrm{~s}^{-1}$. At $0^{\circ}$, with the hull aligned parallel to the approaching flow, a single tight flow-parallel rotating vortex originates from the stern

312 (Figures 9a and 9b). A low velocity (Figure 9c) tail extends downstream from the structure.

313 High pressure zones are developed at the bow and stern (Figure 9d) and low pressure zones

314 to the port and starboard of the vessel. Finally, alternating zones of high and low WSS

315 (Figure 9e) and TKE (Figure 9f) originate at the stern, parallel to the approaching flow.

\section{Discussion}

\section{I Flow regimes}

The CFD models (Figures 3-9) successfully capture the following changes in the flow regime in the environment of the wreck site: flow contraction, the generation of a horseshoe vortex in front of the wreck, the formation of lee-wake vortices behind the structure, and increased turbulence and shear stress in the lee of the wreck site. The modelling further demonstrates that horseshoe vortices control scour at the front (upstream face) of the structure, but plays no role in scouring on the lee side of the structure. No horseshoe vortex shedding is observed in CFD simulations. Lee-wake vortices dominate behind the structure, with low pressure zones in the lee of the wreck capturing flow. The amplification and reduction of wall shear stress and turbulent kinetic energy in the lee of the vessel form distinctive patterns in relation to flow direction, with strongly developed areas of amplified and reduced wall shear stress and turbulent kinetic energy demonstrating good spatial correlation with each other. 
336 When the outputs of the CFD models are compared to existing wreck scour classification

337 schemes derived from real-world data (Caston, 1979; Quinn, 2006) and laboratory

338 experiments (Saunders, 2005; Testik et al., 2005), strong correlation is observed between

339 the morphology and orientation of elevated wall shear stress (WSS) and turbulent kinetic

340 energy (TKE) in the CFD models and the location of scour features in the scour

341 classifications. The spatial correlation between zones of elevated TKE and scour is most

342 notable. Figure 10 shows the interpreted relationship between the erosional and

343 depositional patterns formed in the wake of the wreck as a function of orientation to peak

344 tidal flow derived from the CFD modelling. Scour patterns in the classification are mapped

345 from zones of elevated TKE, and depositional patterns are mapped from zones of reduced

346 TKE. The CFD modelling and interpretation is validated by comparison with multibeam

347 echosounder derived elevation models of real world wreck sites (Plets et al. 20I I) collected

348 off the south coast of England (Figure I la) and the north east coast of Ireland (Figure I I b).

349 Both of these study sites are characterized by non-cohesive sandy seafloors and bi-

350 directional current regimes, analogous to the CFD model environment.

352 For wrecks lying at $90^{\circ}$ to flow, the CFD model predicts twin symmetrical wake scours

353 extending downstream and local scour developed around the bow and stern of the vessel

354 (Figure II), with an area of deposition (thicker sediment) between the two wake scour

355 features. When compared to real-world wreck sites ( $A$ and B in Figure I la), the correlation

356 between the modelled and real world environments is convincing. The more complex

357 arrangement of erosion and deposition imaged at site $B$ is due to the fact that the wreck is

358 broken in two around midhips, presenting a more complex obstacle to flow.

360 At an orientation of $75^{\circ}$, the CFD model predicts two asymmetric wake scours and the

361 development of local scour features at the bow and stern, with higher TKE values (deeper

362 and steeper scour) at the bow, facing into the flow. Areas of deposition are predicted on the

363 outside of the wake scours, parallel to peak flow, and immediately in the lee of the vessel,

364 where TKE and shear stress levels are reduced (Figures 4 and 10).

At an orientation of $60^{\circ}$, the initially separate twin scour hollows converge into one with distance from the vessel (Figure 10). Local scour is developed at the bow and stern, with a

368 deeper and more extensive scour feature developed around the bow, facing the incoming

369 flow. Zones of deposition are located in the immediate lee of the vessel and as two slightly

370 asymmetric ridges extending parallel to the main wake scour. 
372 At an orientation of $45^{\circ}$, a single broad wake scour feature is interpreted, with local scour

373 developed at the bow. Two asymmetric depositional areas are predicted along the edges of

374 the wake scour, parallel to peak flow, with the depositional tail from the stern (the end

375 facing away from flow) longer and broader than the tail from the bow end. When compared

376 to a similar real-world wreck site ( $\mathrm{F}$ in Figure $\mathrm{I} \mathrm{Ib}$ ), the correlation between the predicted

377 patterns and actual patterns is again compelling. Of particular note in this flow scenario is

378 that the highly elevated TKE area in the immediate lee of the vessel (Figure 6) correlate with

379 the steep-sided local scour pits developed on the lee sides of the wreck in response to flood

380 and ebb tides (Figure I I b).

382 At an orientation of $30^{\circ}$, the single broad wake scour developed in the lee of the vessel is

383 bounded by two asymmetric depositional tails, with the tail from the stern side of the vessel

384 more extending the full length of the scour. When compared to an analogous real-world

385 wreck site ( $E$ in Figure $\mathrm{I} \mathrm{lb}$ ), the correlation is once again striking. The depositional tails

386 developed at this wreck site are up to $1 \mathrm{~km}$ long, with local scour developed around the

387 bow of the structure.

389 At an orientation of $15^{\circ}$, the single lee wake scour feature dominates with the asymmetry of 390 the depositional tails increasing further (Figure 10 and Site D in Figure I la). At an

391 orientation of $0^{\circ}$, the signatures of scour and deposition are much weaker, due to the

392 streamlined nature of the vessel lying parallel to peak tidal flow.

394 The processes and patterns inferred from the CFD modelling are in broad agreement with 395 previous studies (Caston 1979; Quinn, 2006; Saunders, 2005; Testik et al., 2005). However,

396 the level of detail generated from the CFD modelling is much greater, and the control

397 environment offered by the numerical modelling allows much greater understanding of

398 linked processes and patterns.

400 An additional minor point of note is that the asymmetry of the modelled shipwreck

401 (streamlined bow and square stern section) leads to slight asymmetry of scour features,

402 particularly in the local scour pits. This result indicates the morphology of the hull of the

403 wreck can impart a significant influence on the morphology (shape, depth etc.) of the scour

404 and depositional features. To date, physical laboratory experiments investigating scour

405 around fully submerged obstacles (e.g. Saunders, 2005; Testik et al. 2005) employed

406 symmetrically shaped objects, resulting in symmetrical scour patterns. 
410 The archaeological implications of this method are significant in that CFD allows us to

411 examine hydrodynamic processes in detail, and make strong links between coupled

412 hydrodynamic and sediment dynamic processes and patterns. The results therefore

413 represent a significant breakthrough in understanding fluid flow and erosional and

414 depositional processes and patterns at submerged wreck sites. Research into processes that

415 form the submerged archaeological record informs effective in-situ conservation and

416 preservation of archaeological sites. Understanding $\mathrm{N}$-transforms at fully submerged sites in

417 detail - specifically, the linked physical processes operating in the water column (hydro-

418 dynamics) and on the sea floor (sediment-dynamics) - can contribute greatly to the effective

419 in-situ conservation of wreck sites.

421 Regular site inspections are an integral part of the overall management strategy for

422 submerged sites (MacLeod and Richards, 20II). Increasingly, baseline morphological surveys

423 of submerged shipwreck sites employ multibeam echosounders (Plets et al., 20I I), with

424 further inspections at (ir)regular intervals to assess change in site integrity (Manders, 2009;

425 Quinn and Boland, 2010; Bates et al., 20II; Astley et al., 2014). Over time, this can lead to

426 sophisticated models of erosion and deposition (Manders, 2009; Astley et al., 20 14; Brennan

427 et al., 2016), albeit at a very high financial cost. Another drawback is that these approaches

428 only allow the patterns of erosion and deposition to be investigated, with causative

429 processes only inferred from the results.

431 Conversely, CFD modelling allows us to examine both patterns and processes, and allows us

432 to use high-resolution multibeam echosounder data as model inputs (Smyth and Quinn,

433 2014). CFD modelling is relatively inexpensive, can make use of open-source software (e.g.

434 OpenFOAM), and allows control of the modelling environment, scenario setting, and even

435 hypotheses testing. This approach is required to broaden our understanding of the

436 processes impacting submerged wreck sites, to inform policy makers, and to develop

437 effective mitigation strategies to minimise loss in the face of increasing human (e.g. offshore

438 developments) and natural (e.g. increased storminess associated with climate change)

439 forcing.

441 Due to the vast number of wrecks discovered on and under the seabed, and the prohibitive

442 costs involved in excavating, raising and conserving these structures, the past two decades

443 has seen a move toward in-situ preservation; to protect, monitor, and manage underwater

444 archaeological sites where they lie on the seabed (Gregory et al., 2012). This approach is

445 encouraed in the 200I UNESCO Convention for the Protection of the Underwater Cultural 
446 Heritage (UNESCO, 200I), which advises that underwater cultural heritage should be

447 protected in-situ as a first option and non-intrusive methods to document and study these

448 sites in-situ should be used (Gregory et al., 20I2). The CFD approach used in this study

449 makes important contributions to not only understanding the processes acting on

450 shipwrecks, but also highlights areas where in-situ preservation measures could be

451 concentrated and targeted (in areas of high turbulence and shear stress), and therefore

452 allows the development of sophisticated plans for in-situ preservation.

\section{Acknowledgements}

The MBES data presented in Figure I I contains public sector information, licensed under the Open Government License v2.0, from Fugro EMU. The MBES data presented in Figure I I b contains public sector information, licensed under the Open Government License v2.0, from the Royal Navy. All numerical modelling, data processing and data rendering in this study was conducted in open source software; we acknowledge the OpenFOAM, Paraview, QGIS and Inkscape community and developers. Thanks to Craig Dyer (Fugro EMU) for useful discussion and for pointing us in the direction of the MBES data off Dartmouth. Reviews by two anonymous reviewers greatly improved an earlier version of this manuscript.

\section{References}

Arnold, J.B., Oertling, T.J., Hall, A.W., 1999. The Denbigh Project: initial observations on a

Civil War blockade-runner and its wreck-site. Int. J. Naut. Archaeol. 28, I26-I44.

Astley, A., Dix, J.K., Thompson, C., Sturt, F., 2014. A seventeen year, near-annual, bathymetric time-series of a marine structure (SS Richard Montgomery). In: Cheng, L., Conference on Scour and Erosion. International Conference on Scour and Erosion. Taylor \& Francis, pp 715-724. satellite imagery. J. Archaeol. Sci. 66, I-6.

481 Ballard, R.D., McCann, A.M., Yoeger, D., Whitcomb, L., Mindell, D., Oleson, J., Singh, H., 482 Foley, B., Adams, J., Piechota, D., Giangrande, C., 2000. The discovery of ancient history in 
483

484

485

486

487

488

489

490

491

492

493

494

495

496

497

498

499

500

501

502

503

504

505

506

507

508

509

510

511

512

513

514

515

516

517

the deep sea using advanced deep submergence technology. Deep-Sea Res. Pt I. 47: 15191620.

Ballard, R.D., Stager, L.E., Master, D., Yoerger, D., Mindell, D., Whitcomb, L.L., Singh, H. and Piechota, D., 2002. Iron Age Shipwrecks in Deep Water off Ashkelon, Israel. Am. J. Archaeol. 106, 151-168.

Bates, C.R., Lawrence, M., Dean, M., Robertson, P., 20II. Geophysical Methods for WreckSite Monitoring: the Rapid Archaeological Site Surveying and Evaluation (RASSE) programme. Int. J. Naut. Archaeol. 40, 404-4I6.

Brennan, M.L., Davis, D., Ballard, R.D., Trembanis, A.C., Vaughan, V.I., Krumholz, J.S.,

Delgado, J.P., Roman, C.N., Smart, C., Bell, K.L.C., Duman, M., DuVal, C., 2016.

Quantification of bottom trawl fishing damage to ancient shipwreck sites. Mar. Geol. 37I, 82-88.

Caston, G.F., 1979. Wreck marks: indicators of net sand transport. Mar. Geol. 33, 193-204.

Gregory, D., Jensen, P., Strætkvern, K., 2012. Conservation and in situ preservation of wooden shipwrecks from marine environments. J. Cult. Herit. I3, SI39-SI48.

Hatton, K.A., Smith, H.D. and Foster, D.L., 2004. The Scour and Burial of Submerged Mines, Eos Trans. AGU. 84 (52). Ocean Sci. Meet. Suppl. Abstract OS52B-I8.

Hesp, P.A., Smyth, T.A.G., Nielsen, P., Walker, I.J., Bauer, B.O., Davidson-Arnott, R., 2015. Flow deflection over a foredune. Geomorphology. 230, 64-74.

Manders, M., 2009. Multibeam recording as a way to monitor shipwreck sites. In: MACHU Final Report NR. 3 - Managing Cultural Heritage Underwater, pp. 59-66.

MacLeod, I.D., Richards, V.L., 20II. In situ conservation surveys of iron shipwrecks in Chuuk Lagoon and the impact of human intervention. AICCM Bull. 32, 106-122.

McCann, A.M. and Oleson, J.P., 2004. Deep Water Shipwrecks off Skerki Bank: The 1997 Survey. J. Roman Archaeol. Supp. Ser. 58. Portsmouth, R.I. 
518 McNinch, J.E. Wells, J.T and Drake, T.G., 200I. The fate of artifacts in an energetic, shallow-

519 water environment: scour and burial at the wreck site of Queen Anne's Revenge.

520 Southeastern Geol. 40, 19-27.

Muckelroy, K., 1978. Maritime archaeology, Cambridge University Press, Cambridge.

O' Shea, J.M., 2002. The archaeology of scattered wreck-sites: formation processes and shallow water archaeology in western Lake Huron. Int. J. Naut. Archaeol. 3I, 2 I I-227.

Plets, R., Quinn, R., Forsythe, W., Westley, K., Bell, T., Benetti, S., McGrath, F., Robinson, R.,

528 201 I. Using Multibeam Echo-Sounder Data to Identify Shipwreck Sites: archaeological

529 assessment of the Joint Irish Bathymetric Survey data. Int. J. Naut. Archaeol. 40, 87-98.

531 Quinn, R., 2006. The role of scour in shipwreck site formation processes and the preservation of wreck-associated scour signatures in the sedimentary record - evidence from seabed and sub-surface data. . J. Archaeol. Sci. 33, 1419-1432.

Quinn, R. and Boland, D., 2010. The role of time-lapse bathymetric surveys in assessing morphological change at shipwreck sites. J. Archaeol. Sci. 37, 2938-2946. sediments. In: Keith, M.E. (Ed.), Site Formation Processes of Submerged Shipwrecks. University Press of Florida, Gainesville, pp. 70-89. Evidence for palaeo-scour marks. Int. J. Naut. Archaeol. 26, 3-16. archaeological case studies. Unpublished PhD Thesis, University of Southampton. OS2IB-12I7.

552 Smyth, T.A.G., Jackson, D.W.T., Cooper, J.A.G., 20I3, Three dimensional airflow patterns 553 within a coastal trough-bowl blowout during fresh breeze to hurricane force winds. Aeolian 554 Res. 9, III-123. 
556 Smyth, TAG, Quinn, R., 20I4. The role of computational fluid dynamics in understanding

557 shipwreck site formation processes. J. Archaeol. Sci. 45, 220-225.

561 Sumer, B.M., Christiansen, N. and Fredsoe, J., 1997. The horseshoe vortex and vortex

562 shedding around a vertical wall-mounted cylinder exposed to waves, Journal of Fluid

563 Mechanics, 332: 41-70.

564

565 Sumer, B.M., Whitehouse, R., Torum, A., 200I, Scour around coastal structures: a summary

566 of recent research. Coast. Eng. 44, 153-190.

568 Stewart, D.J., 1999. Formation processes affecting submerged archaeological sites: An

569 overview, Geoarchaeology. 14, 565-587.

571 Testik, F.Y., Voropayev, S.I. and Fernando, H.J.S., 2005. Flow around a short horizontal

572 bottom cylinder under steady and oscillatory flows. Phys. Fluids. 17, 47-103.

574 Trembanis, A.C., McNinch, A.C., 2003. Predicting Scour and Maximum Settling Depths of

575 Shipwrecks: A Numeric Simulation of the Fate of Queen Anne's Revenge. Proceedings of

576 Coastal Sediments, Clearwater Beach, Florida.

Uchupi, E., Muck, M.T., Ballard, R.D., 1988. The geology of the Titanic site and vicinity, Deep-Sea Res. Pt A. 35, 1093-III0.

581 UNESCO, 200I. Convention on the Protection of the Underwater Cultural Heritage.

582 http://www.unesco.org/new/en/culture/themes/underwater-cultural-heritage/200I-

583 convention/ Accessed 13.08.2016

584

585 Voropayev, S.I., Testik, F.Y., Fernando, H.J.S., Boyer, D.L., 2003. Burial and scour around

586 short cylinder under progressive shoaling waves. Ocean Eng. 30, I647-1667.

588 Ward, I.A.K., Larcombe, P. and Veth, P., 1999. A New Process-based Model for Wreck Site 589 Formation. J. Archaeol. Sci. 26, 56I-570. 
591 Wheeler, A., 2002. Environmental Controls on Shipwreck Preservation: The Irish Context.

592 J. Archaeol. Sci. 29, II49-II59.

593

594 Whitehouse, R.J.S., 1998. Scour at marine structures, Thomas Telford Ltd., London.

595

596 Whitehouse, R.J.S., Harris, J.M., Sutherland, J., Rees, J., 2010. The nature of scour

597 development and scour protection at offshore windfarm foundations, Mar Poll Bull. 62, 73-

59888.

599

600 Whitehouse, R.J.S., Sutherland, J., Harris, J.M., 20II. Evaluating scour at marine gravity

601 structures, Maritime Eng. 164 (MA4), 143-157.

602

603 Yakhot, V., Orszag, S.A., Thangam, S., Gatski, T.B., Speziale, C.G., 1992. Development of

604 turbulence models for shear flows by a double expansion technique. Phys. Fluids A. 4, I5I0-

6051520.

606

607

Figures

608

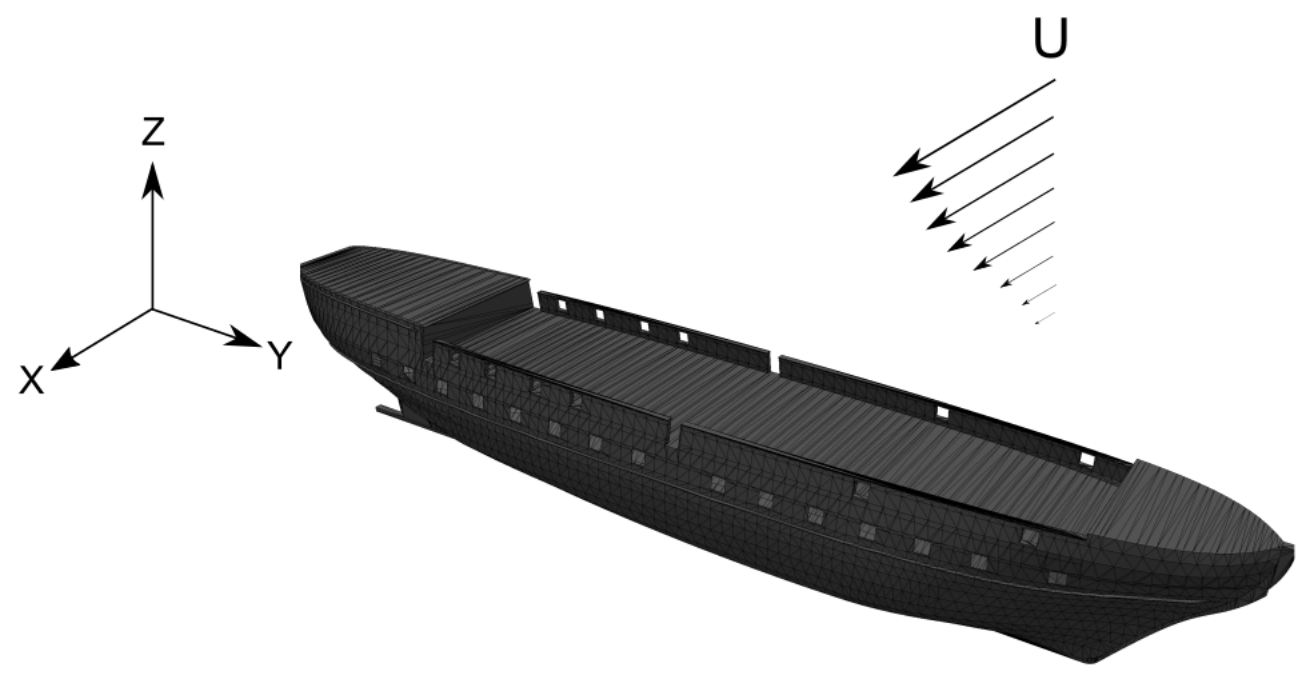

609

610 Figure I: Illustration of the hull structure and coordinate system used in the CFD modelling.

611 Model parameters: $\mathrm{U}=$ free-stream water velocity, $\mathrm{z}=$ height above bed, $\mathrm{x}=$ distance

612 downstream of the hull model, $y=$ distance in line with the hull orientation. 

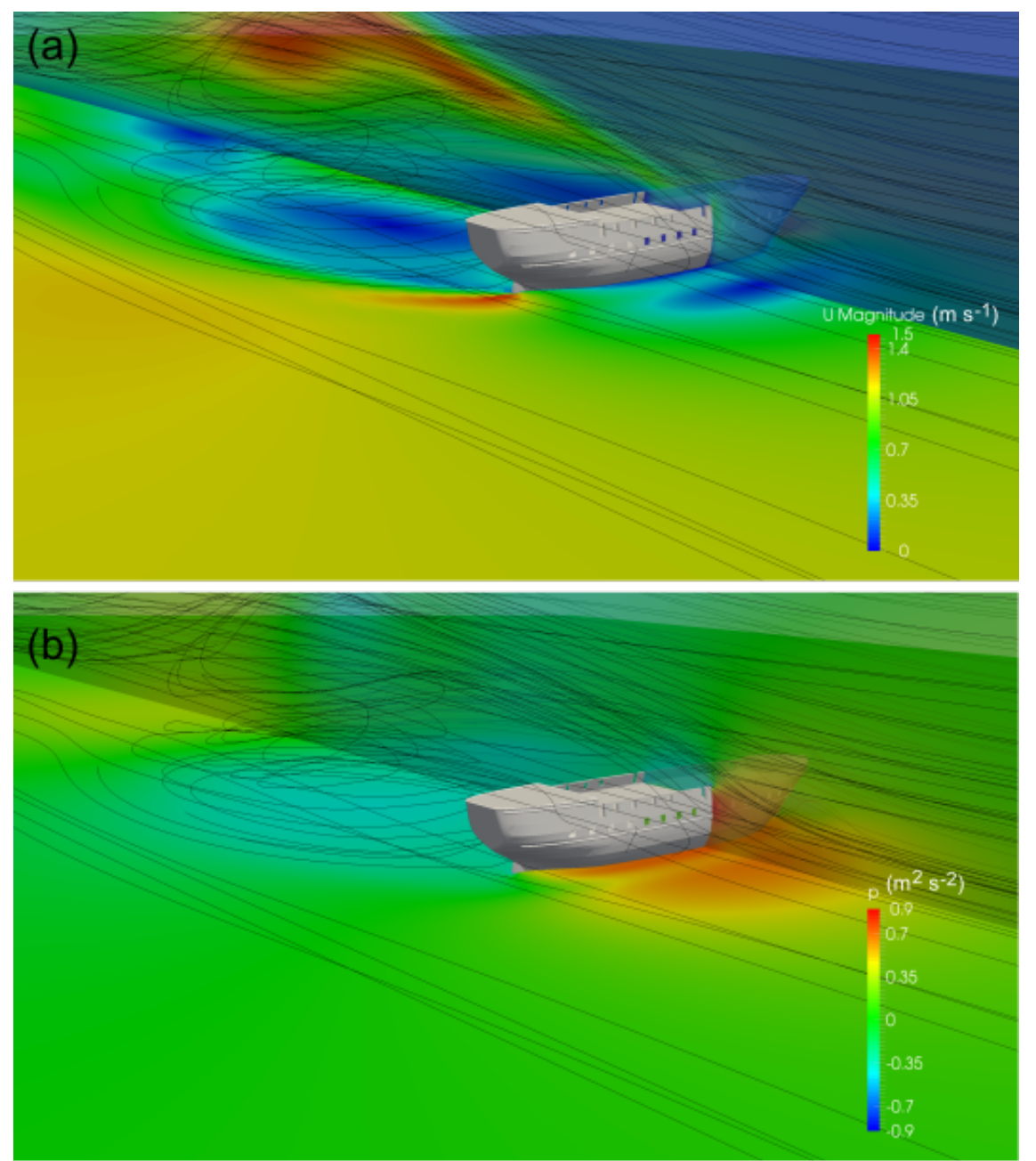

(c)

614

615

616 Figure 2: (a) 3D simulation with 2D vertical slice of the velocity field around the hull

617 structure with flowlines superimposed, (b) 3D simulation with 2D vertical slice of the

618 pressure field around the hull structure, and (c) 3D simulation with 2D vertical slice of the

619 TKE field around the hull structure. 

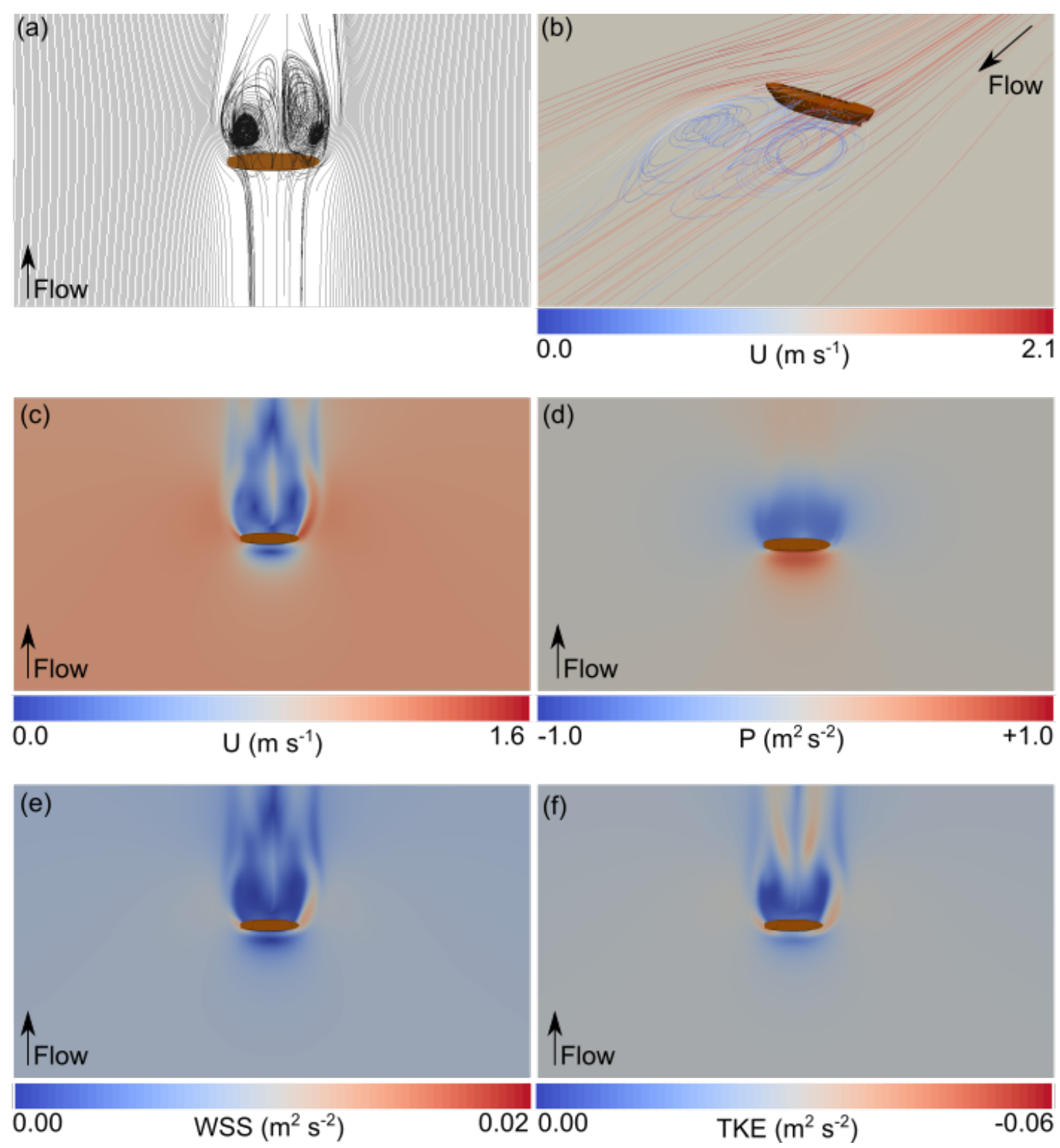

622

623 Figure 3: Hull at $90^{\circ}$ to flow. (a) 2-dimensional flowlines, (b) 3-dimensional flowlines, (c)

624 velocity, (d) pressure, (e) wall shear stress, and (f) turbulent kinetic energy maps derived 625 from CFD model. 

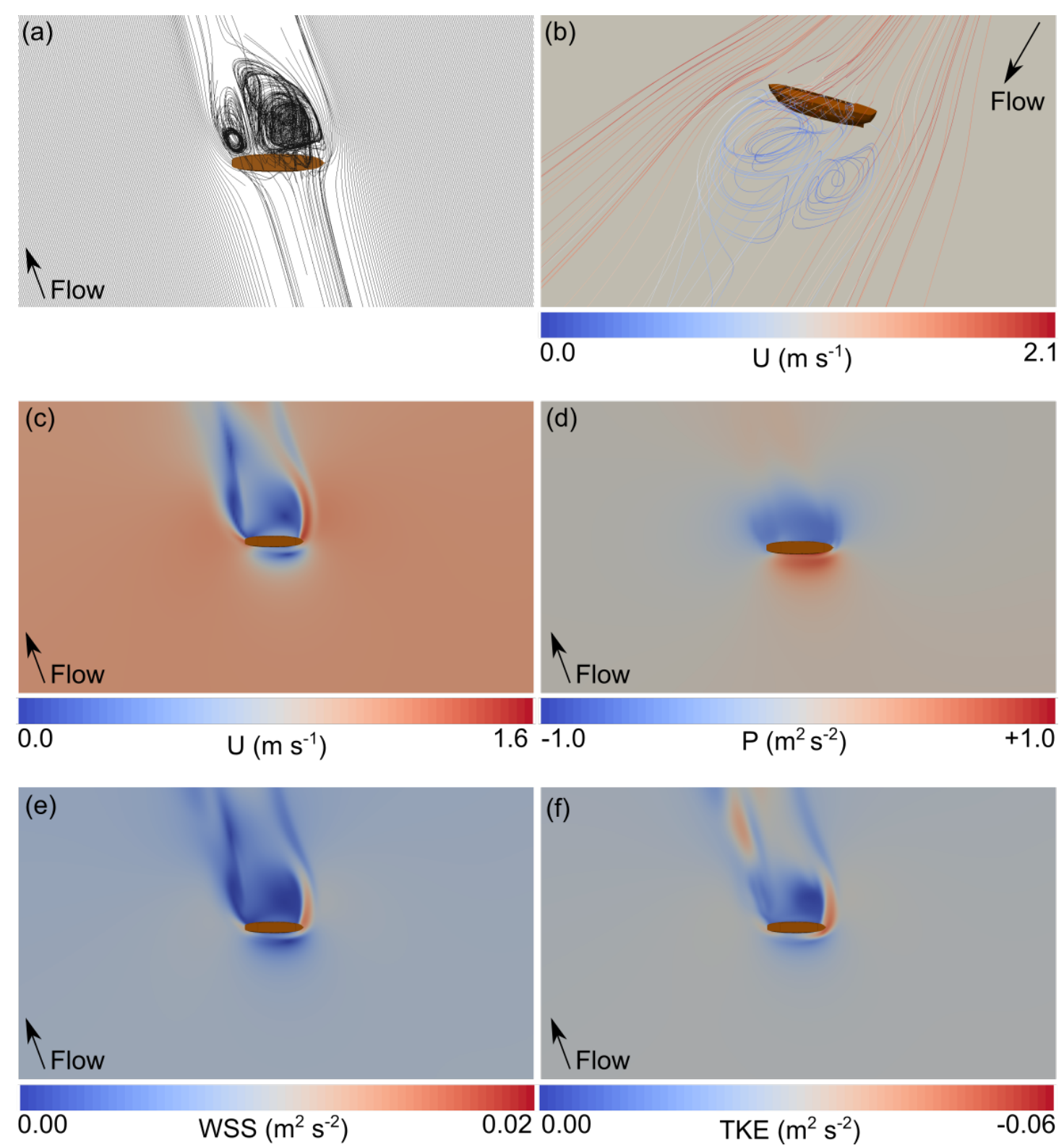

627

628 Figure 4: Hull at $75^{\circ}$ to flow. (a) 2-dimensional flowlines, (b) 3-dimensional flowlines, (c)

629 velocity, (d) pressure, (e) wall shear stress, and (f) turbulent kinetic energy maps derived 630 from CFD model. 

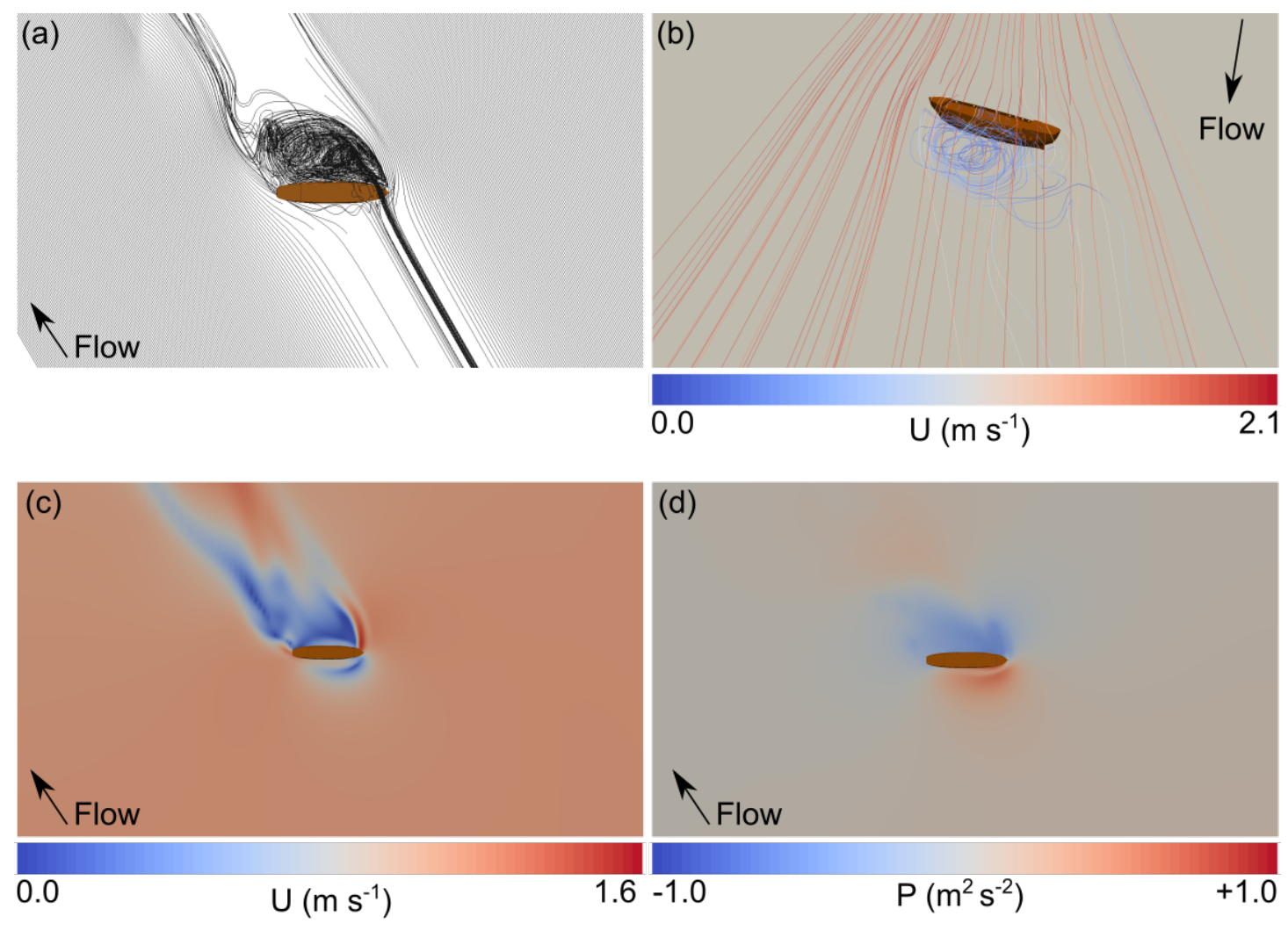

632
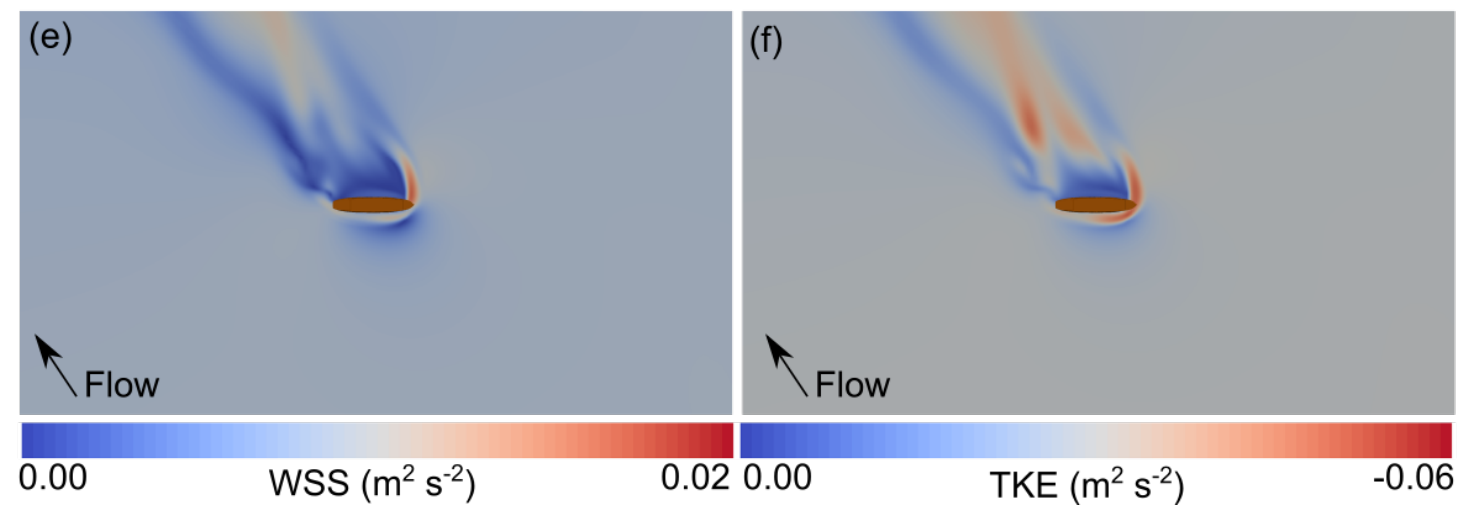

633

634 Figure 5: Hull at $60^{\circ}$ to flow. (a) 2-dimensional flowlines, (b) 3-dimensional flowlines, (c)

635 velocity, (d) pressure, (e) wall shear stress, and (f) turbulent kinetic energy maps derived 636 from CFD model. 

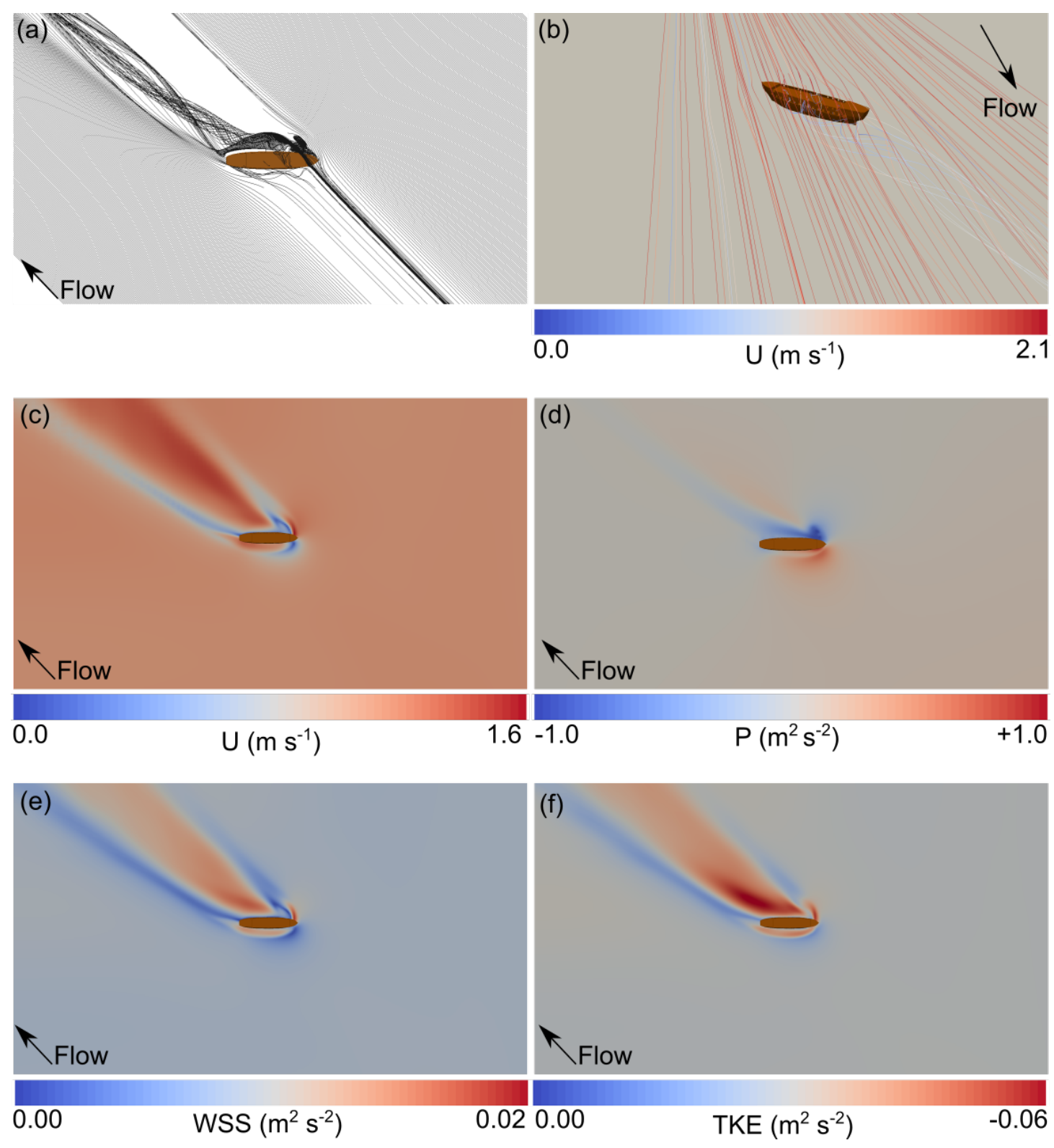

638

639

640 Figure 6: Hull at $45^{\circ}$ to flow. (a) 2-dimensional flowlines, (b) 3-dimensional flowlines, (c)

641 velocity, (d) pressure, (e) wall shear stress, and (f) turbulent kinetic energy maps derived 642 from CFD model.

643 

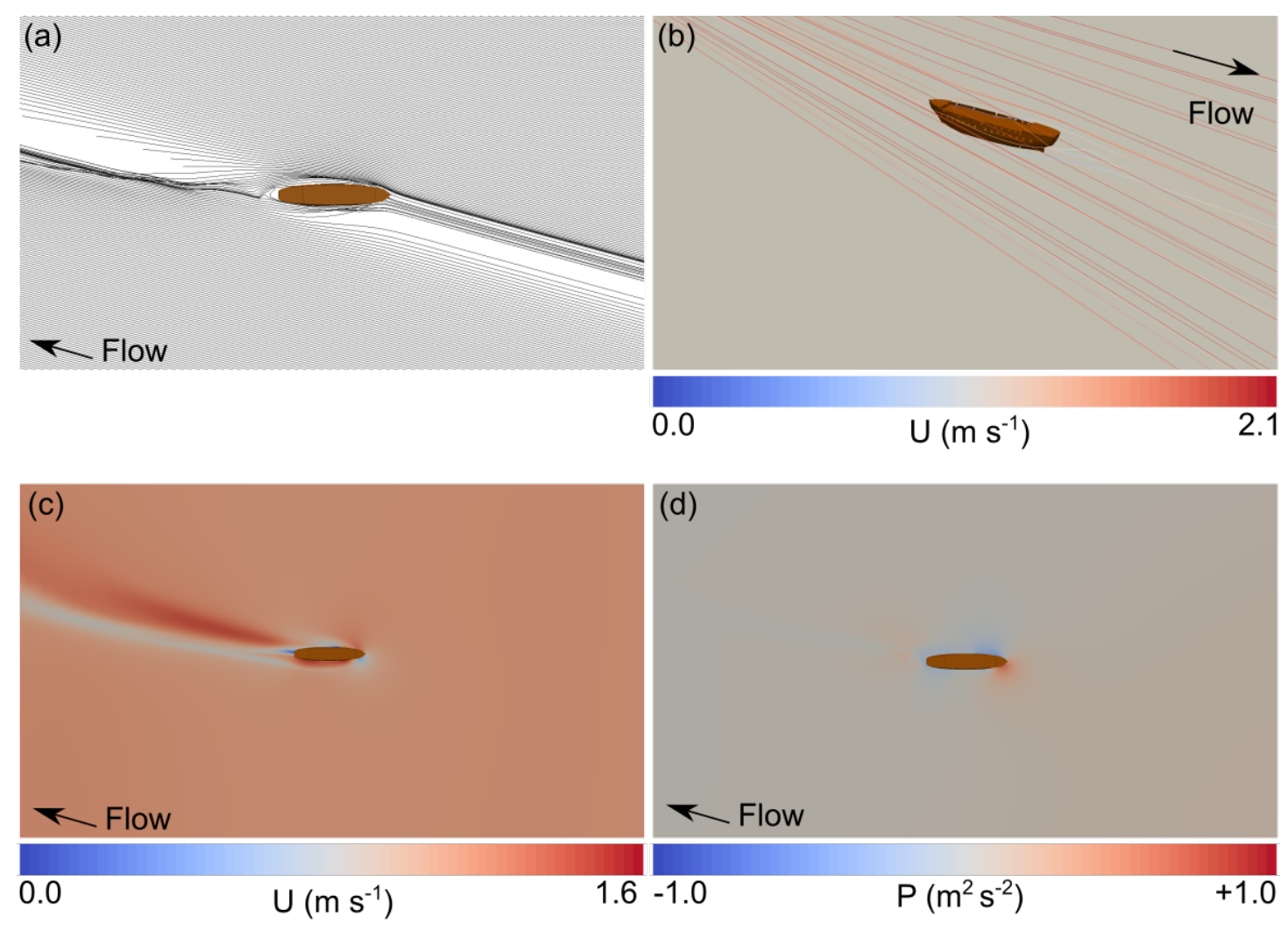

644

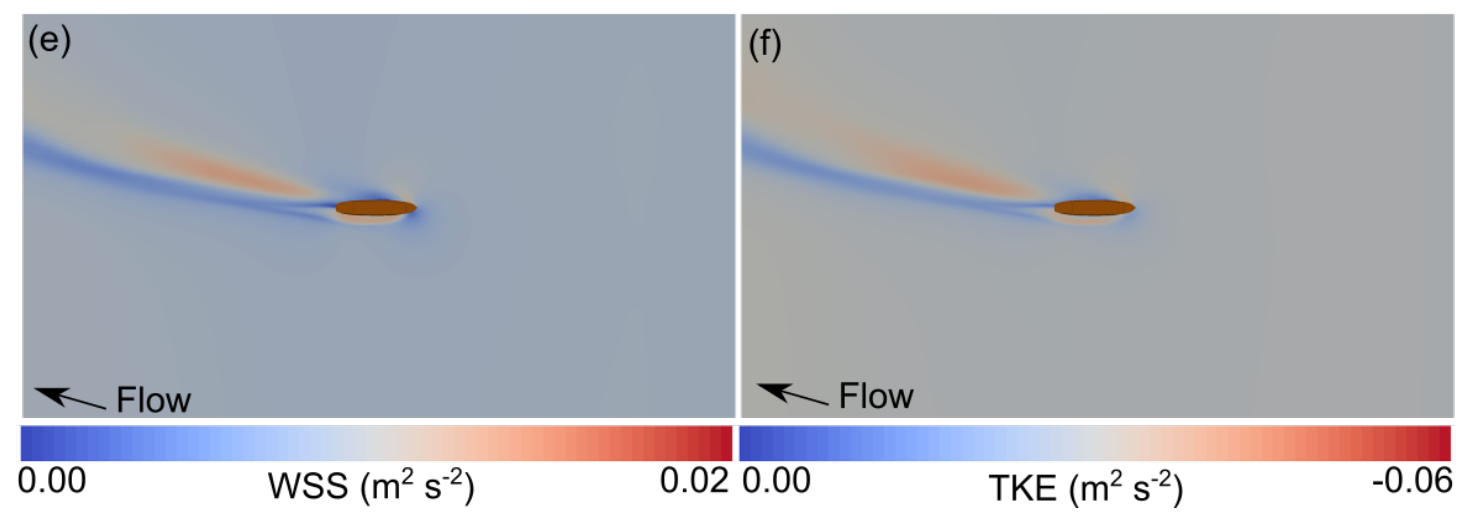

645

646 Figure 7: Hull at $30^{\circ}$ to flow. (a) 2-dimensional flowlines, (b) 3-dimensional flowlines, (c)

647 velocity, (d) pressure, (e) wall shear stress, and (f) turbulent kinetic energy maps derived 648 from CFD model. 

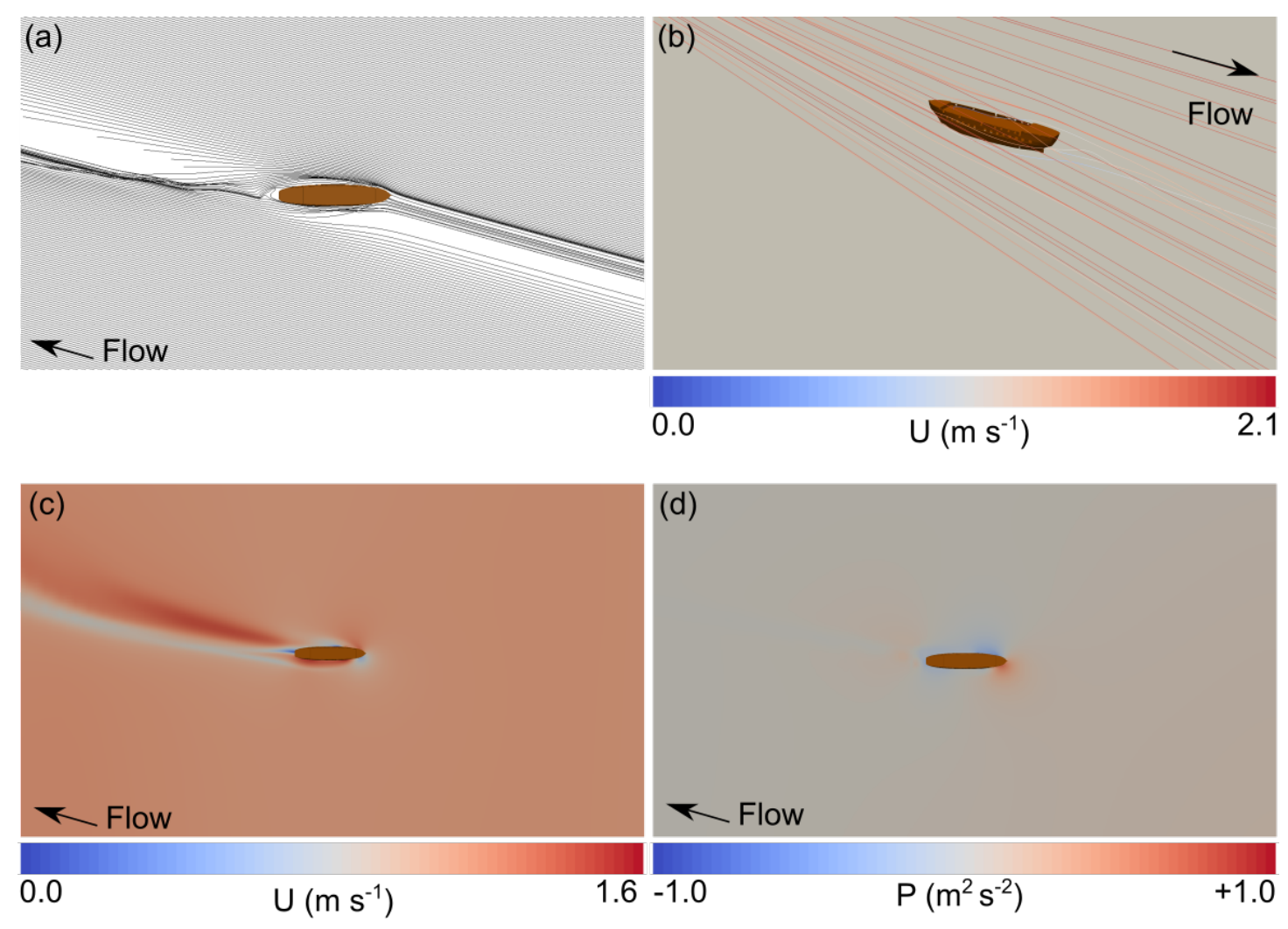

650

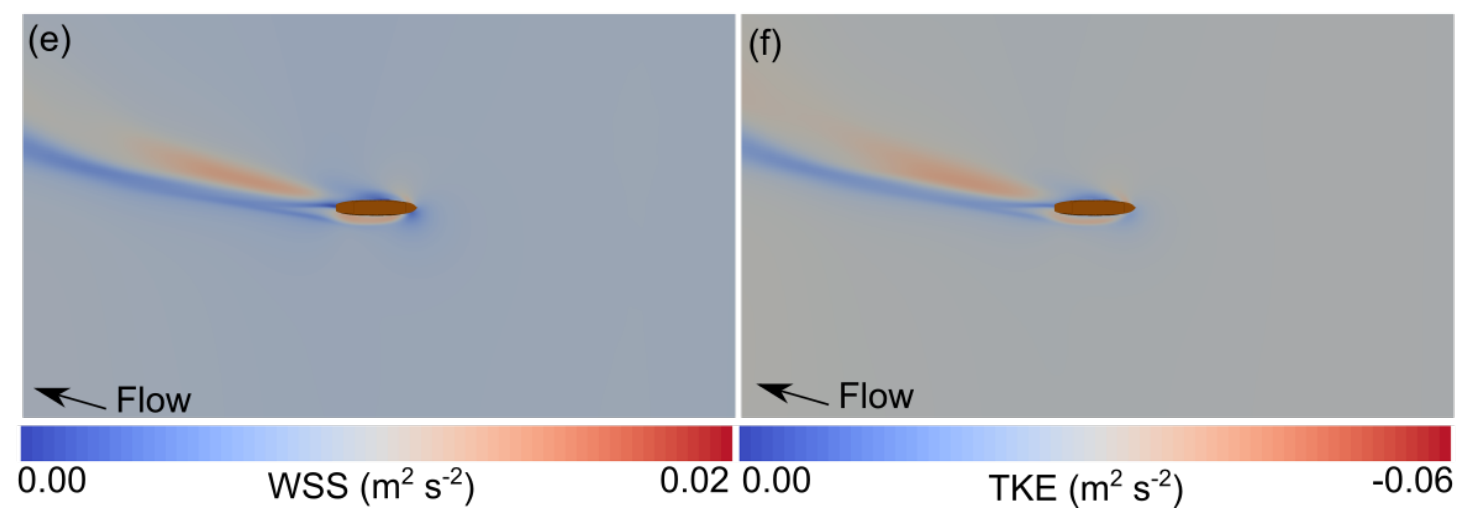

651

652 Figure 8: Hull at $15^{\circ}$ to flow. (a) 2-dimensional flowlines, (b) 3-dimensional flowlines, (c)

653 velocity, (d) pressure, (e) wall shear stress, and (f) turbulent kinetic energy maps derived

654 from CFD model.

655 

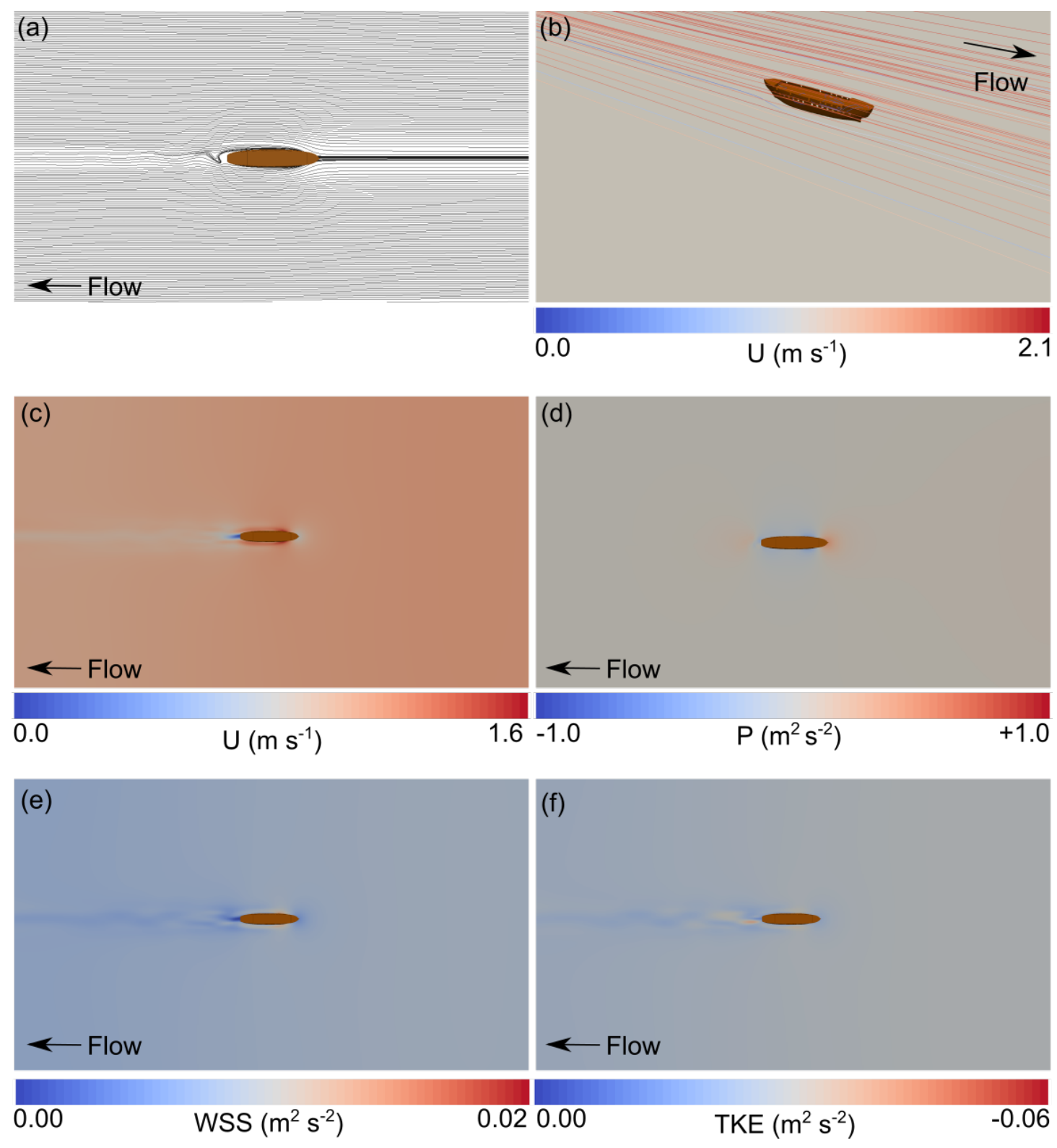

656

657

658 Figure 9: Hull at $0^{\circ}$ to flow. (a) 2-dimensional flowlines, (b) 3-dimensional flowlines, (c)

659 velocity, (d) pressure, (e) wall shear stress, and (f) turbulent kinetic energy maps derived

660 from CFD model. 


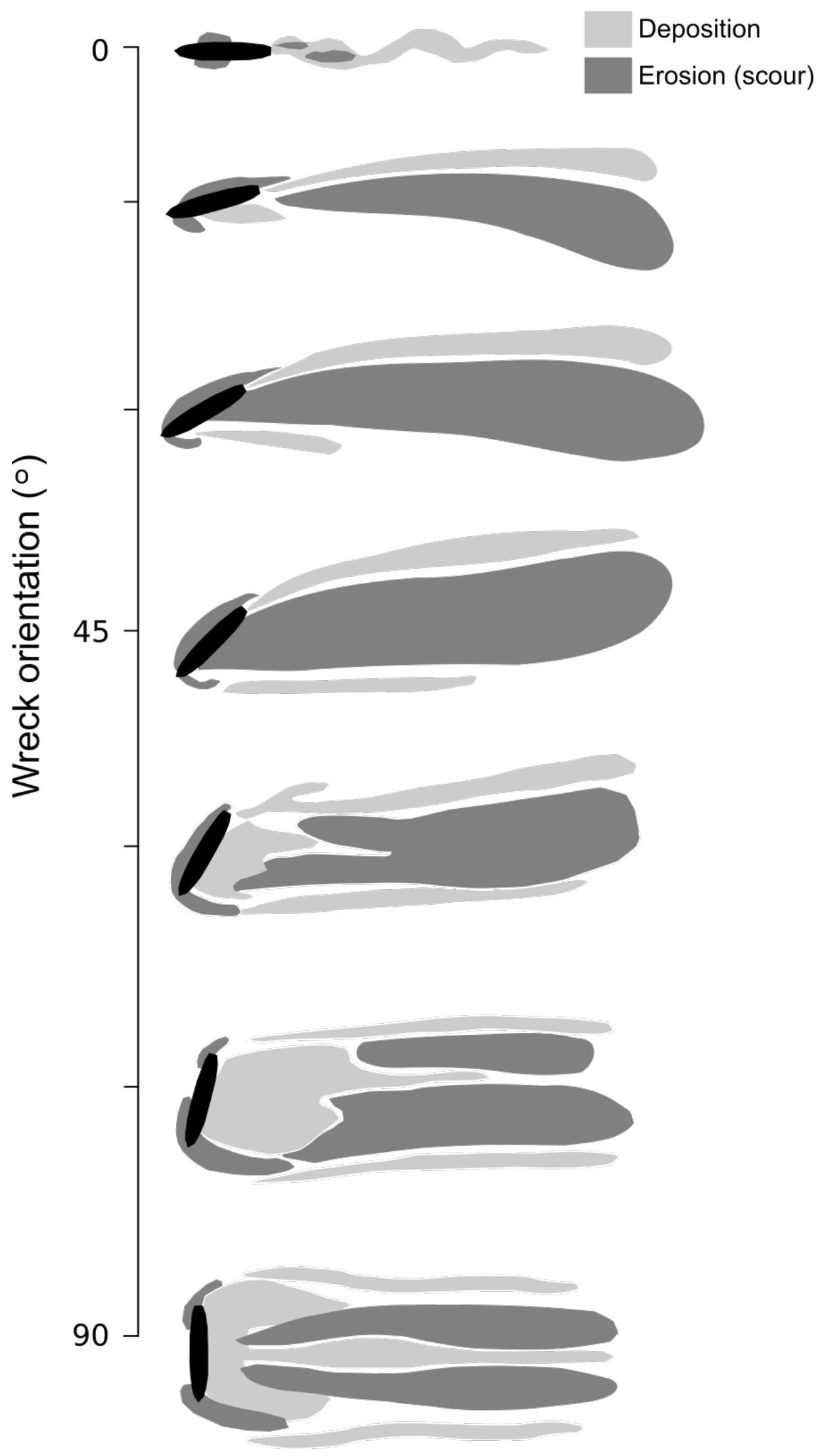

663

664 Figure 10: Wreck associated erosional and depositional patterns around fully submerged 665 shipwrecks inferred from the output of CFD models. 

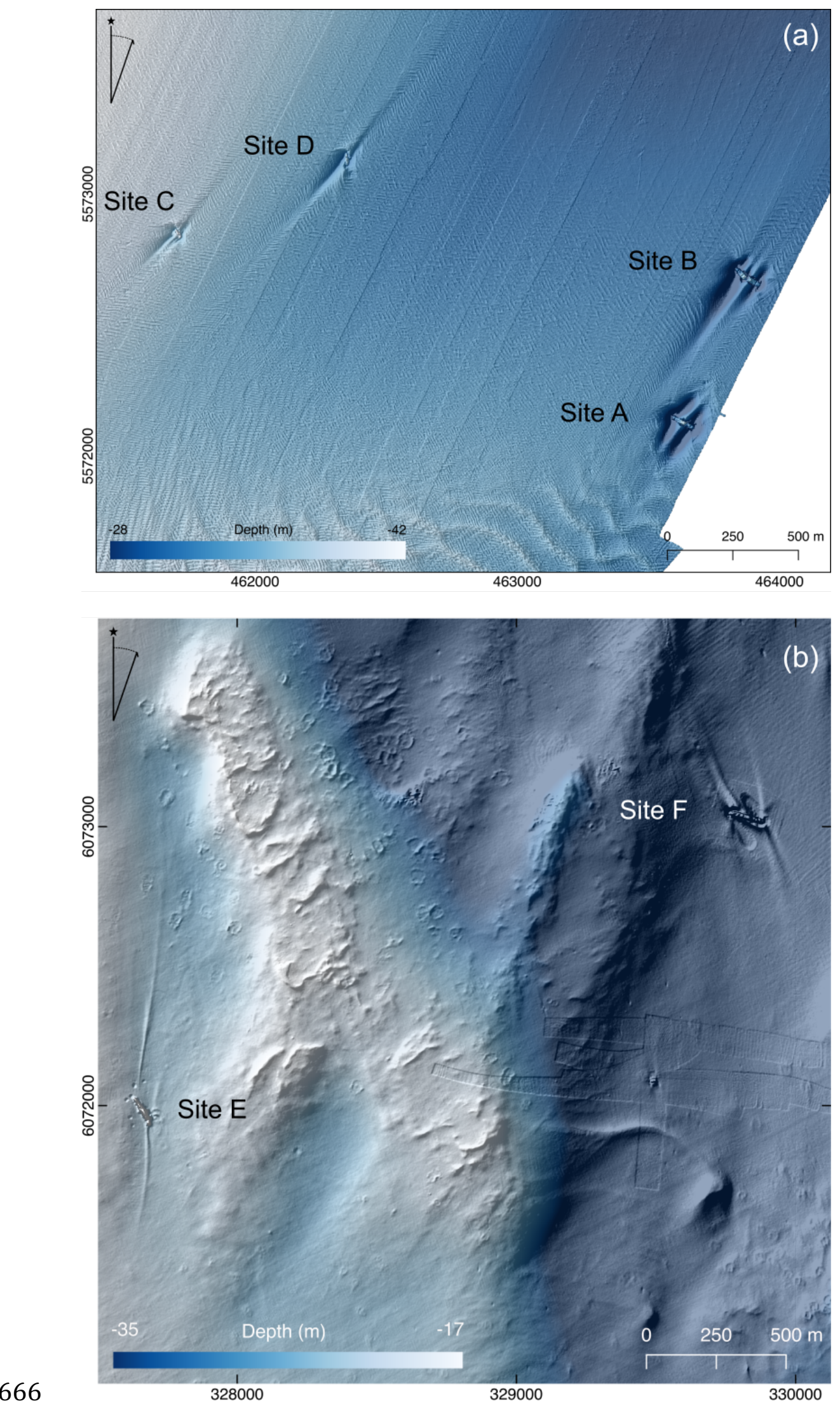

668 Figure II: Multibeam echosounder data from shipwreck sites off (a) Dartmouth on the south 669 coast of England, and (b) Belfast on the north east coast of Ireland. 
670 Table 1 Summary of flow geometry and patterns of velocity (U), pressure (P), shear stress (WSS), and turbulence (TKE) from the CFD

\begin{tabular}{|c|c|c|c|c|c|}
\hline Angle $\left({ }^{\circ}\right)$ & Flow geometry & $\mathrm{U}$ & $\mathrm{P}$ & WSS & TKE \\
\hline 90 & $\begin{array}{l}\text { Symmetrical flow patterns; } \\
\text { horseshoe vortices form } \\
\text { upstream; flow contraction at bow } \\
\text { and stern; counter-rotating } \\
\text { symmetrical low-velocity vortex } \\
\text { pair forms downstream of wreck. }\end{array}$ & $\begin{array}{l}\text { Low } U \text { zones upstream and } \\
\text { downstream of wreck; high flow- } \\
\text { parallel } U \text { regions originate at bow } \\
\text { and stern. }\end{array}$ & $\begin{array}{l}\text { High P zone immediately } \\
\text { upstream of wreck; low P zone } \\
\text { downstream. }\end{array}$ & $\begin{array}{l}\text { High flow-parallel WSS regions } \\
\text { originate at bow and stern; low } \\
\text { WSS zones upstream and } \\
\text { downstream of wreck. }\end{array}$ & $\begin{array}{l}\text { Low TKE zones upstream and } \\
\text { downstream of wreck; high flow- } \\
\text { parallel TKE regions originate at } \\
\text { bow and stern and in two } \\
\text { symmetric diverging flow-parallel } \\
\text { regions downstream. }\end{array}$ \\
\hline 75 & $\begin{array}{l}\text { Increasing asymmetry of flow } \\
\text { upstream and downstream; } \\
\text { asymmetric counter-rotating low- } \\
\text { velocity vortex pair forms } \\
\text { downstream; in-flow vortex } \\
\text { dominates. }\end{array}$ & $\begin{array}{l}\text { Low } U \text { zones upstream and } \\
\text { downstream of wreck; high } U \\
\text { region originates at upstream end; } \\
\text { low } U \text { region originates at } \\
\text { downstream end. }\end{array}$ & $\begin{array}{l}\text { High P zone immediately } \\
\text { upstream of wreck; low P zone } \\
\text { downstream. }\end{array}$ & $\begin{array}{l}\text { Low WSS zones upstream and } \\
\text { downstream of wreck; high WSS } \\
\text { region originates at upstream end; } \\
\text { low WSS region originates at } \\
\text { downstream end. }\end{array}$ & $\begin{array}{l}\text { Low TKE zones upstream and } \\
\text { downstream of wreck; high TKE } \\
\text { region originates at upstream end; } \\
\text { low TKE region originates at } \\
\text { downstream end; two high TKE } \\
\text { regions in wake of hull begin to } \\
\text { converge downstream. }\end{array}$ \\
\hline 60 & $\begin{array}{l}\text { Increasing asymmetry of flow } \\
\text { upstream and downstream; } \\
\text { transition from asymmetric double } \\
\text { to single vortex downstream; in- } \\
\text { flow vortex dominates. }\end{array}$ & $\begin{array}{l}\text { Low } U \text { zones upstream and } \\
\text { downstream of wreck; high } U \\
\text { region originates at upstream end; } \\
\text { low } U \text { region originates at } \\
\text { downstream end; complex } U \text { field } \\
\text { in wake of hull. }\end{array}$ & $\begin{array}{l}\text { High P zone immediately } \\
\text { upstream of wreck; low P zone } \\
\text { downstream elongated parallel to } \\
\text { peak flow. }\end{array}$ & $\begin{array}{l}\text { Low WSS zones upstream and } \\
\text { downstream of wreck; high WSS } \\
\text { region originates at upstream end; } \\
\text { low WSS region originates at } \\
\text { downstream end; complex WSS } \\
\text { field in wake of hull; two high } \\
\text { WSS regions in wake of hull } \\
\text { converge downstream. }\end{array}$ & $\begin{array}{l}\text { Low TKE zones upstream and } \\
\text { downstream of wreck; high TKE } \\
\text { region originates at upstream end; } \\
\text { low TKE region originates at } \\
\text { downstream end; complex WSS } \\
\text { field in wake of hull; two high TKE } \\
\text { regions in wake of hull converge } \\
\text { downstream. }\end{array}$ \\
\hline 45 & $\begin{array}{l}\text { Single tight flow-aligned vortex } \\
\text { forms downstream. }\end{array}$ & $\begin{array}{l}\text { Single high } U \text { zone dominates in } \\
\text { wake of hull; bounded by two low } \\
\cup \text { flow-parallel regions originating } \\
\text { at bow and stern. }\end{array}$ & $\begin{array}{l}\text { High P zone immediately } \\
\text { upstream of wreck, concentrated } \\
\text { around upstream end; low } P \text { zone } \\
\text { downstream elongated parallel to } \\
\text { peak flow. }\end{array}$ & $\begin{array}{l}\text { Single high WSS zone dominates } \\
\text { in wake of hull; bounded by two } \\
\text { low WSS flow-parallel regions } \\
\text { originating at bow and stern. }\end{array}$ & $\begin{array}{l}\text { Single high TKE zone dominates } \\
\text { in wake of hull; bounded by two } \\
\text { low TKE flow-parallel regions } \\
\text { originating at bow and stern. }\end{array}$ \\
\hline 30 & $\begin{array}{l}\text { Single open flow-aligned vortex } \\
\text { forms downstream. }\end{array}$ & $\begin{array}{l}\text { Single high flow-parallel U zone } \\
\text { dominates in wake of hull; } \\
\text { bounded by two low } U \text { flow- } \\
\text { parallel regions originating at bow } \\
\text { and stern. }\end{array}$ & $\begin{array}{l}\text { High P zone immediately } \\
\text { upstream of wreck, concentrated } \\
\text { around upstream end; paired } \\
\text { high-low P zone downstream } \\
\text { elongated parallel to peak flow. }\end{array}$ & $\begin{array}{l}\text { Single high flow-parallel WSS } \\
\text { zone dominates in wake of hull; } \\
\text { bounded by two low WSS flow- } \\
\text { parallel regions originating at bow } \\
\text { and stern. }\end{array}$ & $\begin{array}{l}\text { Single high flow-parallel TKE zone } \\
\text { dominates in wake of hull; } \\
\text { bounded by two low TKE flow- } \\
\text { parallel regions originating at bow } \\
\text { and stern. }\end{array}$ \\
\hline 15 & $\begin{array}{l}\text { Single tight flow-aligned vortex } \\
\text { forms downstream. }\end{array}$ & $\begin{array}{l}\text { Single high flow-parallel } U \text { zone } \\
\text { dominates in wake of hull; } \\
\text { bounded by a low } U \text { flow-parallel } \\
\text { region originating at stern. }\end{array}$ & $\begin{array}{l}\text { High P zone immediately } \\
\text { upstream of wreck, concentrated } \\
\text { around upstream end. }\end{array}$ & $\begin{array}{l}\text { Single high flow-parallel WSS } \\
\text { zone dominates in wake of hull; } \\
\text { bounded by a low WSS flow- } \\
\text { parallel region originating at stern. }\end{array}$ & $\begin{array}{l}\text { Single high flow-parallel TKE zone } \\
\text { dominates in wake of hull; } \\
\text { bounded by a low TKE flow- } \\
\text { parallel regions originating at }\end{array}$ \\
\hline
\end{tabular}


contraction at upstream en

only; single downstream vortex

s immediately adjacent to

Single flow-parallel low-velocity

zone in wake of hull.

High $\mathrm{P}$ zone upstream and

downstream of hull; low $P$ zones

at port and starboard. stern.

Flow-parallel laterally extensive low-velocity zone in wake of hul
and another at upstream end.

Flow-parallel laterally extensive low/high-velocity zone in wake of hull. 